\title{
A Kinetic Model for Predicting the Relative Humidity in Modified Atmosphere Packaging and Its Application in Lentinula edodes Packages
}

\author{
Li-xin Lu, ${ }^{1,2}$ Ya-li Tang, ${ }^{1,2}$ and Su-yue Lu' \\ ${ }^{1}$ Jiangnan University, Wuxi 214122, China \\ ${ }^{2}$ Jiangsu Province Key Laboratory of Advanced Food Manufacturing Equipment and Technology, Wuxi 214122, China \\ Correspondence should be addressed to Li-xin Lu; lulx@jiangnan.edu.cn
}

Received 13 June 2013; Accepted 7 August 2013

Academic Editor: Changfeng Ge

Copyright ( $\odot 2013$ Li-xin Lu et al. This is an open access article distributed under the Creative Commons Attribution License, which permits unrestricted use, distribution, and reproduction in any medium, provided the original work is properly cited.

\begin{abstract}
Adjusting and controlling the relative humidity $(\mathrm{RH})$ inside package is crucial for ensuring the quality of modified atmosphere packaging (MAP) of fresh produce. In this paper, an improved kinetic model for predicting the RH in MAP was developed. The model was based on heat exchange and gases mass transport phenomena across the package, gases heat convection inside the package, and mass and heat balances accounting for the respiration and transpiration behavior of fresh produce. Then the model was applied to predict the RH in MAP of fresh Lentinula edodes (one kind of Chinese mushroom). The model equations were solved numerically using Adams-Moulton method to predict the RH in model packages. In general, the model predictions agreed well with the experimental data, except that the model predictions were slightly high in the initial period. The effect of the initial gas composition on the RH in packages was notable. In MAP of lower oxygen and higher carbon dioxide concentrations, the ascending rate of the $\mathrm{RH}$ was reduced, and the $\mathrm{RH}$ inside packages was saturated slowly during storage. The influence of the initial gas composition on the temperature inside package was not much notable.
\end{abstract}

\section{Introduction}

Modified atmosphere packaging (MAP) is an important technology which can efficiently maintain quality and extend shelf life of produce. However, most polymeric films used in MAP have lower water vapor permeation rates relative to larger respiration rates of fresh produce; excessively high $\mathrm{RH}$ inside package may occur, and it may lead to undesirable results such as moisture condensation, microbial growth, and shortened shelf life [1-4]. Some methods were adopted to reduce the $\mathrm{RH}$ inside the package for extending shelf life of produce [5-8].

Research on the mechanism of the RH change in MAP is very important for proper control of the $\mathrm{RH}$ and the quality of fresh produce. The RH in MAP is influenced by many factors such as respiration and transpiration of produce, the permeability of the packaging films, storage conditions, and packaging technology. Because of the RH inside the package with dynamic changes during storage, and the difficulty to accurately determine the respiration and transpiration process, little work has been done on predicting the $\mathrm{RH}$ in MAP.

It is critical to establish the kinetic model of produce respiration and transpiration in order to predict and control the change of the RH in MAP. Transpiration rate model in MAP system has not been well developed mostly because transpiration phenomena on product surface due to respiratory heat has not been well acknowledged at changing $\mathrm{O}_{2}$ and $\mathrm{CO}_{2}$ environment [9]. A model was developed to predict the change of temperature and $\mathrm{RH}$ in MAP containing blueberry and moisture absorbent $[9,10]$. A simple model to predict the quality changes of apples inside the packages was proposed [11]. Some effect factors and kinetic processes were neglected in the above models, such as the temperature difference of the fresh produce, the package headspace and the surrounding, gases heat convection inside the package, and heat change caused by gas transmission across the package. 
In MAP of nonrespiring foods, several mathematical models for gas diffusion and sorption processes and predicting the temperature change inside package were developed. Simpson proposed a model for gas diffusion and gas sorption processes [12] and then developed a model to predict consequences of temperature abuse on shelf life of pacific hake packaged in a MAP system [13]. The model included simultaneous heat and mass transfer phenomena coupled with a predictive shelf-life model and was solved using an explicit finite difference scheme. Simulated results were in good agreement with experimental results. Recently, these predictive models were successfully applied to study and determine the optimal conditions for packaging scallops in a modified atmosphere system [14].

In this study, an improved kinetic model for predicting the $\mathrm{RH}$ in MAP of produce was developed. The model was based on heat exchange and gases mass transport phenomena across the package, gases heat convection inside the package, and mass and heat balances accounting for the respiration and transpiration behavior of fresh produce. To verify the model, a set of testing systems was established to measure the gas concentrations, $\mathrm{RH}$, and temperature in MAP. The $\mathrm{RH}$ and temperature were valuated with experimental data of fresh Lentinula edodes (one kind of Chinese mushroom) packaged in modified atmospheres.

\section{The Improved Kinetic Model for Predicting the RH in Map of Produce}

Produce released respiratory energy during respiration in MAP. When released, respiratory heat partly is absorbed by produce leading to the rising of self temperature, and part of the heat is absorbed by free water of produce to vaporize water vapor. Meanwhile, the rest of respiratory heat is released to package.

According to law of heat conservation, a heat balance relation inside package can be represented as

$$
Q_{r}=Q_{p}+Q_{t}+Q_{g}+Q_{f}+Q_{e}
$$

where $Q_{r}$ is the respiratory heat of produce $\left(J \cdot h^{-1}\right), Q_{p}$ is the heat absorbed by produce $\left(\mathrm{J} \cdot \mathrm{h}^{-1}\right), Q_{t}$ is the heat absorbed by water vapor during evaporation $\left(\mathrm{J} \cdot \mathrm{h}^{-1}\right), Q_{g}$ is the heat absorbed by gas inside package $\left(\mathrm{J} \cdot \mathrm{h}^{-1}\right), \mathrm{Q}_{f}$ is the heat absorbed by package $\left(\mathrm{J} \cdot \mathrm{h}^{-1}\right)$, and $Q_{e}$ is the heat change caused by gas transmission across package $\left(\mathrm{J} \cdot \mathrm{h}^{-1}\right)$.

2.1. Respiratory Heat of Produce. Considering the respiration heat of produce as the only internal heat, it could be described using the following respiratory equation [9]

$$
\mathrm{C}_{6} \mathrm{H}_{12} \mathrm{O}_{6}+6 \mathrm{O}_{2} \longrightarrow 6 \mathrm{CO}_{2}+\mathrm{H}_{2} \mathrm{O}+2816 \mathrm{~kJ}
$$

Respiration rate is generally described as $\mathrm{O}_{2}$ consumption rate $R_{\mathrm{O}_{2}}$ or $\mathrm{CO}_{2}$ evolution rate $R_{\mathrm{CO}_{2}}$. Respiration rate of produce could be estimated using Michaelis-Menten type of equations [15]:

$$
\begin{aligned}
R_{\mathrm{O}_{2}} & =\frac{V_{m 1}\left[\mathrm{O}_{2}\right]}{K_{m 1}+\left(1+\left[\mathrm{CO}_{2}\right] / K_{u 1}\right)\left[\mathrm{O}_{2}\right]}, \\
R_{\mathrm{CO}_{2}} & =\frac{V_{m 2}\left[\mathrm{O}_{2}\right]}{K_{m 2}+\left(1+\left[\mathrm{CO}_{2}\right] / K_{u 2}\right)\left[\mathrm{O}_{2}\right]},
\end{aligned}
$$

where $R_{\mathrm{O}_{2}}, R_{\mathrm{CO}_{2}}$ are $\mathrm{O}_{2}$ consumption rate, $\mathrm{CO}_{2}$ evolution rate, respectively $\left(\mathrm{mL} \cdot \mathrm{kg} \cdot \mathrm{h}^{-1}\right),\left[\mathrm{O}_{2}\right],\left[\mathrm{CO}_{2}\right]$ are $\mathrm{O}_{2}, \mathrm{CO}_{2}$ concentration inside package, respectively (\%), $V_{m 1}, V_{m 2}$ are maximum $\mathrm{O}_{2}, \mathrm{CO}_{2}$ consumption rate, respectively $\left(\mathrm{mL} \cdot \mathrm{kg} \cdot \mathrm{h}^{-1}\right)$, $K_{m 1}, K_{m 2}$ are Michaelis constants of $\mathrm{O}_{2}, \mathrm{CO}_{2}$ consumption, respectively (\%), and $k_{u 1}, k_{u 2}$ are inhibition constants in $\mathrm{O}_{2}$, $\mathrm{CO}_{2}$ consumption, respectively (\%).

The quantities of $\mathrm{O}_{2}$ and $\mathrm{CO}_{2}$ inside package are dynamically changeable in storage. On the basis of gas mass balance across the package, the change of $\mathrm{O}_{2}, \mathrm{CO}_{2}$ concentration inside package can be obtained [16] by

$$
\begin{aligned}
& \frac{d\left[\mathrm{O}_{2}\right]}{d t} \\
& =(100)\left[\frac{P_{\mathrm{O}_{2}} \cdot A_{p} \cdot P_{\mathrm{atm}}\left(\left[\mathrm{O}_{2}\right]_{\mathrm{out}} / 100-\left[\mathrm{O}_{2}\right]_{\mathrm{in}} / 100\right)}{z}\right. \\
& \left.-R_{\mathrm{O}_{2}} \cdot W_{p}\right] \times V^{-1} \\
& \frac{d\left[\mathrm{CO}_{2}\right]}{d t} \\
& =(100) \\
& \begin{aligned}
\times\left[\frac{P_{\mathrm{Co}_{2}} \cdot A_{p} \cdot P_{\mathrm{atm}}\left(\left[\mathrm{CO}_{2}\right]_{\mathrm{out}} / 100-\left[\mathrm{CO}_{2}\right]_{\mathrm{in}} / 100\right)}{z}\right. \\
\left.\quad+R_{\mathrm{CO}_{2}} \cdot W_{p}\right] \times V^{-1},
\end{aligned}
\end{aligned}
$$

where $P_{\mathrm{O}_{2}}, P_{\mathrm{CO}_{2}}$ are film permeabilities to $\mathrm{O}_{2}, \mathrm{CO}_{2}$, respectively $\left(\mathrm{mL} \cdot \mathrm{m} \cdot \mathrm{m}^{-2} \cdot \mathrm{h}^{-1} \cdot \mathrm{atm}^{-1}\right), A_{p}$ is surface area of package $\left(\mathrm{m}^{2}\right), z$ is the thickness of package film $(\mathrm{m}), W_{p}$ is the mass of produce $(\mathrm{kg}), p_{\mathrm{atm}}$ is the pressure of $1 \mathrm{~atm}$, and $V$ is the free volume of package $(\mathrm{mL})$.

Many researches indicate that respiratory quotient RQ $\left(R_{\mathrm{CO}_{2}} / R_{\mathrm{O}_{2}}\right)$ changes between 0.7 and 1.3. Therefore, respiration rates $R$ of produce can be described by the average of $\mathrm{O}_{2}$ consumption and $\mathrm{CO}_{2}$ evolution rate $[9,11]$ :

$$
R=\frac{R_{\mathrm{CO}_{2}}+R_{\mathrm{O}_{2}}}{2} .
$$

Based on (2)-(5), the respiratory heat of produce in unit time can be represented as $[9,11]$

$$
Q_{r}=\left(\frac{2816}{6}\right) R W_{p} .
$$


2.2. Heat Absorbed by Produce. The heat absorbed by produce results in the change of temperature of produce. The mass of produce may decrease because of evaporation. Considering it as insignificant to the initial mass of produce, the loss of mass is negligible in this study. So the heat absorbed by produce in unit time can be represented as [17]

$$
Q_{p}=C_{p} W_{p} \frac{d T_{p}}{d t}
$$

where $C_{p}$ is the specific heat of surface tissue of produce $\left(\mathrm{J} \cdot \mathrm{kg}^{-1} \cdot \mathrm{k}^{-1}\right), T_{p}$ is the temperature on produce surface $(\mathrm{k})$.

2.3. Heat Absorbed by Water Vapor during Evaporation. It is known that the heat absorbed by free water of unit mass to vaporize is definite in a certain condition. In unit time, the heat absorbed by water vapor during evaporation is $[9,11]$

$$
Q_{t}=L_{m} \lambda \text {, }
$$

where $L_{m}$ is the rate of water evaporation from produce to package $\left(\mathrm{kg} \cdot \mathrm{h}^{-1}\right), \lambda$ is coefficient of evaporation heat $\left(\mathrm{J} \cdot \mathrm{kg}^{-1}\right)$.

2.4. The Heat Absorbed by Gas inside Package. The heat absorbed by gas inside package consists of the following processes.

(1) Gas around produce inside package absorbs heat and results in rise in temperature.

(2) The difference in temperature of gas between near and far away from the produce makes convection of gas inside package and results in exchange of heat.

2.4.1. Heat Absorbed by Gas around the Produce. The heat absorbed by gas around the produce in unit time is expressed by [17]

$$
Q_{g 1}=W_{s} C_{s} \frac{d T_{s}}{d t},
$$

where $W_{s}$ is the mass of gas around the produce $(\mathrm{kg}), C_{s}$ is the specific heat of gas $\left(\mathrm{J} \cdot \mathrm{kg}^{-1} \cdot \mathrm{k}^{-1}\right)$, and $T_{s}$ is the temperature of gas around produce $(\mathrm{k})$.

2.4.2. Heat Exchanged by Convection of Gas inside Package. In the closed container, convection is one natural heat-releasing convection caused by the difference in temperature between gas near produce surface and free space inside package. Hence, Nusselt and Grashof rules could be used to describe the process.

It is well known that Nusselt number $\mathrm{Nu}$ is the function of Grashof number Gr and Prandtl number Pr on the condition of natural heat-releasing convection. To simpler geometric shapes, the following equations could be applied to deal with these problems in engineering [17]:

$$
\mathrm{Nu}=\frac{H L}{k}=c\left(\mathrm{Gr}_{I} \cdot \operatorname{Pr}\right)^{m}
$$

where $H$ is the coefficient of heat-exchange convection $\left(\mathrm{J} \cdot \mathrm{h}^{-1} \cdot \mathrm{m} \cdot \mathrm{k}^{-2}\right), L$ is the qualitative length of Grashof number $(\mathrm{m}), k$ is the coefficient of heat conduction of gas $\left(\mathrm{J} \cdot \mathrm{h}^{-1} \cdot \mathrm{m} \cdot \mathrm{k}^{-1}\right), c$ is the proportion constant, $\mathrm{Gr}_{L}$ is the Grashof number when the qualitative length equals $L$, and the value of exponent $m$, according to experience, is 1/4 for laminar flow and $1 / 2$ for overfall flow [17].

To simplify analysis, a series of experimental formulas have been proposed. For example, on the condition of the natural convection inside the vertical or horizontal closed cylinder, Nu can be expressed as [17]

$$
\mathrm{Nu} \equiv \frac{H D}{k}=0.55 \cdot\left(\mathrm{Gr}_{L} \cdot \mathrm{Pr}\right)^{1 / 4}
$$

where $D$ is the diameter of cylinder $(\mathrm{m})$.

The coefficients of heat-exchanging convection $H$ can be obtained from (10)

$$
H=\frac{c k\left(\mathrm{Gr}_{L} \cdot \operatorname{Pr}\right)^{m}}{L} .
$$

Therefore, the exchanged convective heat in unit time can be expressed as

$$
Q_{g 2}=H A\left(T_{s}-T_{h}\right) \text {, }
$$

where $T_{h}$ is the temperature far away from the heat-releasing surface $(\mathrm{k})$, namely, the temperature of headspace gas inside package.

As a result, in unit time, the heat absorbed by gas inside package is written as

$$
Q_{g}=Q_{g 1}+Q_{g 2}
$$

2.5. Heat Absorbed by Package. The heat absorbed by package is caused by the heat transfer produced by the difference in temperatures between inside and outside of the package. Rigid package consists of the packaging bracket and sealed film, while soft package is made up of films. For universality, rigid package is discussed in this study.

The heat absorbed by a rigid package in unit time can be represented as

$$
Q_{f}=Q_{f t}+Q_{f m}=W_{t} C_{t} \frac{d T_{t}}{d t}+W_{m} C_{m} \frac{d T_{m}}{d t}
$$

where $Q_{f t}, Q_{f m}$ are the heat absorbed by packaging bracket, sealed film, respectively $\left(\mathrm{J} \cdot \mathrm{h}^{-1}\right), W_{t}, W_{m}$ is the mass of bracket, package film, respectively $(\mathrm{kg}), C_{t}, C_{m}$ is the specific heat of bracket material, sealed film, respectively $\left(\mathrm{J} \cdot \mathrm{kg}^{-1} \cdot \mathrm{k}^{-1}\right)$, and $T_{t}$, $T_{m}$ is the temperature of bracket, sealed film, respectively (k).

2.6. Heat Change Caused by Gas Transmission across the Package. Gas exchanges exist across the packaging film because of the difference of gas pressures inside and outside the package during storage. It results in the heat change inside package.

The gas energy is the sum of the internal energy and pressure static energy [18]. The internal energy of perfect 
gas, determined only by temperature, is produced by heat movement of gas molecules. Average movement energy $E_{k}$ of a single gas molecule has a direct ratio relationship with absolute temperature [18]:

$$
E_{k}=\frac{i}{2} k_{B} T=\frac{i}{2} n \cdot R_{c} \cdot T
$$

where $i$ is the free degree of gas molecule, $k_{B}$ is Boltzmann constant $\left(1.38 \times 10^{-23} \mathrm{~J} \cdot \mathrm{k}^{-1}\right), R_{c}$ is gas constant $\left(8.314 \mathrm{~J} \cdot \mathrm{mol}^{-1} \cdot \mathrm{k}^{-1}\right), T$ is the absolute temperature of gas $(\mathrm{k})$, and $n$ is the mol number of gas (mol). [18]

The pressure static energy $E_{s}$ of gas can be described as

$$
E_{s}=n R_{c} T \text {. }
$$

The free degrees of $\mathrm{CO}_{2}, \mathrm{H}_{2} \mathrm{O}$, and $\mathrm{O}_{2}$ molecules are 6, 12 , and 5, respectively [18]. Generally, the gas environment in MAP contains lower $\mathrm{O}_{2}$ concentration, higher $\mathrm{CO}_{2}$ and water vapor concentrations relative to those of outside package. the energy which $\mathrm{CO}_{2}$ and water vapor permeate out of package in unit time can be described as

$$
\begin{aligned}
Q_{g \text {-out }}= & \left(\frac{d n_{\mathrm{CO}_{2}}}{d t} \times \frac{6}{2}+\frac{d n_{\mathrm{H}_{2} \mathrm{O}}}{d t} \times \frac{12}{2}\right) R_{c} T_{h} \\
& +\left(\frac{d n_{\mathrm{CO}_{2}}}{d t}+\frac{d n_{\mathrm{H}_{2} \mathrm{O}}}{d t}\right) R_{c} T_{h} \\
= & \left(4 \frac{d n_{\mathrm{CO}_{2}}}{d t}+7 \frac{d n_{\mathrm{H}_{2} \mathrm{O}}}{d t}\right) R_{c} T_{h},
\end{aligned}
$$

where $n_{\mathrm{CO}_{2}}, n_{\mathrm{H}_{2} \mathrm{O}}$ are the mol number of $\mathrm{CO}_{2}$, water vapor permeating out of package, respectively.

Meanwhile, the energy which $\mathrm{O}_{2}$ permeates into package in unit time can be denoted as

$$
Q_{g-\text { in }}=\frac{7}{2} \frac{d n_{\mathrm{O}_{2}}}{d t} R_{c} T_{\text {out }}
$$

where $n_{\mathrm{O}_{2}}$ is the mol number of $\mathrm{O}_{2}$ permeating into package, $T_{\text {out }}$ is storage temperature of package (k).

The heat change caused by gas transmission across the package is

$$
Q_{e}=Q_{g \text {-in }}-Q_{\text {g-out }} \cdot
$$

In terms of the results above, the heat balance relation in MAP can be represented as

$$
\begin{aligned}
R W_{p}\left(\frac{Q}{6}\right)= & W_{p} C_{p} \frac{d T_{p}}{d t}+L_{m} \lambda+H A\left(T_{s}-T_{h}\right) \\
& +W_{s} C_{s} \frac{d T_{s}}{d t}+W_{t} C_{t} \frac{d T_{t}}{d t} \\
& +W_{m} C_{m} \frac{d T_{m}}{d t}+\frac{7}{2} \frac{d n_{\mathrm{O}_{2}}}{d t} R_{c} T_{\text {out }} \\
& -\left(4 \frac{d n_{\mathrm{CO}_{2}}}{d t}+7 \frac{d n_{\mathrm{H}_{2} \mathrm{O}}}{d t}\right) R_{c} T_{h} .
\end{aligned}
$$

2.7. Predicting the $R H$ in MAP. There are two sources that cause the change of quantity of water vapor inside package:

(1) the mass of water vapor produced by transpiration of produce,

(2) the mass of water vapor penetrated out or into packages across the package film.

2.7.1. The Mass Change of Water Vapor Caused by Transpiration of Produce. The mass of water vapor produced by transpiration of produce in unit time, namely, transpiration rate of water vapor, can be obtained according to (21) as follows:

$$
\begin{aligned}
L_{m}=\left[\frac{\mathrm{Q}}{6} R W_{p}-W_{p} C_{p} \frac{d T_{p}}{d t}-H A\left(T_{s}-T_{h}\right)\right. \\
\quad-W_{s} C_{s} \frac{d T_{s}}{d t}-W_{t} C_{t} \frac{d T_{t}}{d t} \\
\quad-W_{m} C_{m} \frac{d T_{m}}{d t}-\frac{7}{2} \frac{d n_{\mathrm{O}_{2}}}{d t} R_{c} T_{\text {out }} \\
\left.+\left(4 \frac{d n_{\mathrm{CO}_{2}}}{d t}+7 \frac{d n_{\mathrm{H}_{2} \mathrm{O}}}{d t}\right) R_{c} T_{h}\right] \times \lambda^{-1} .
\end{aligned}
$$

2.7.2. The Mass Change of Water Vapor Penetrated out or into Packages across the Package Film. The mass of water vapor permeating across the package in unit time is represented as [9]

$$
\frac{d m_{\mathrm{H}_{2} \mathrm{O}}}{d t}=\left[\frac{P_{\mathrm{H}_{2} \mathrm{O}} \cdot A_{p} \cdot\left(p_{\mathrm{H}_{2} \mathrm{O}}^{\text {out }}-p_{\mathrm{H}_{2} \mathrm{O}}^{\text {in }}\right)}{z}\right]\left[\frac{0.018 p_{\mathrm{atm}}}{R_{c} T_{h}}\right],
$$

where $m_{\mathrm{H}_{2} \mathrm{O}}$ is the mass of water vapor $(\mathrm{kg}), P_{\mathrm{H}_{2} \mathrm{O}}$ is the package film permeability to water vapor $\left(\mathrm{mL} \cdot \mathrm{m} \cdot \mathrm{m}^{-2} \cdot \mathrm{h}^{-1} \cdot \mathrm{atm}^{-1}\right)$, and $p_{\mathrm{H}_{2} \mathrm{O}}^{\text {out }}, p_{\mathrm{H}_{2} \mathrm{O}}^{\text {in }}$ are the water vapor pressures outside and inside package, respectively (atm).

2.7.3. The Change of the RH inside Package. The changing rate of mass of water vapor inside the package can be described as

$$
\frac{d H_{\mathrm{in}}}{d t}=\frac{L_{m}-d m_{\mathrm{H}_{2} \mathrm{O}} / d t}{W_{a}}
$$

where $H_{\text {in }}$ is the absolute humidity inside package $\left(\left(\mathrm{kg} \cdot \mathrm{H}_{2} \mathrm{O}\right) \cdot\left(\mathrm{kg}^{-1} \cdot \mathrm{dry} \cdot \mathrm{H}_{2} \mathrm{O}\right)\right), W_{a}$ is the mass of dry air inside package $(\mathrm{kg})$.

The $\mathrm{RH}$ inside package can be denoted as

$$
\mathrm{RH}_{\mathrm{in}}=\frac{H_{\mathrm{in}}}{H_{\mathrm{sp}}}
$$

where $H_{\mathrm{sp}}$ is the absolute humidity of saturated water vapor at corresponding temperature $\left(\left(\mathrm{kg} \cdot \mathrm{H}_{2} \mathrm{O}\right) \cdot\left(\mathrm{kg}^{-1} \cdot \mathrm{dry} \cdot \mathrm{H}_{2} \mathrm{O}\right)\right)$. 


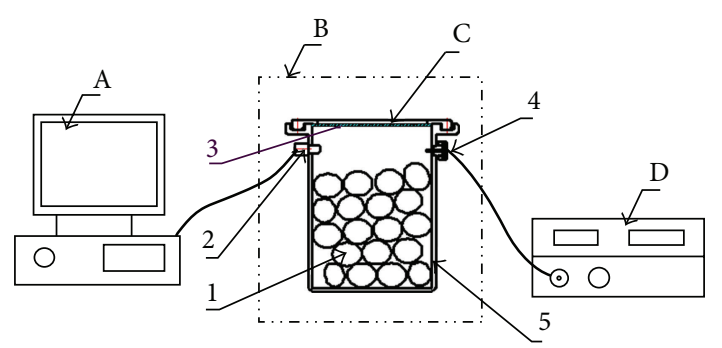

FIGURE 1: Schematic of testing system (A, intelligent measurement system of RH-temperature; B, adjust system of RH-temperature; $\mathrm{C}$, testing jar; $\mathrm{D}$, gas concentration analysis instrument; 1 , samples; 2, sensor of RH-temperature; 3, sealed film/metal cap; 4, pump of gases; 5 , jar body).

\section{Predicting the RH in Map of Lentinula Edodes}

\subsection{Materials and Method}

3.1.1. Fresh Lentinula edodes and Packaging Film. Fieldgrown Lentinula edodes used in this study were grown in Wuxi, China, and harvested at the stage of maturity in March, 2008. Lentinula edodes were then transported to the laboratory within one hour. They were selected for being similar in size and regular in shape.

The low-density polyethylene, $32 \mu \mathrm{m}$ thick (LDPE) (Shenda Flexible Packaging Material Co., Ltd., China), was used for packaging film. The film permeabilities to $\mathrm{O}_{2}$, $\mathrm{CO}_{2}$, and $\mathrm{H}_{2} \mathrm{O}$ were measured by gas permeability testers (Languang Instrument Ltd., China, Model BTY-B1,TSY-T, test precision: $5 \%$ ) under $8^{\circ} \mathrm{C}$. The film permeabilities to $\mathrm{O}_{2}$, $\mathrm{CO}_{2}$, and $\mathrm{H}_{2} \mathrm{O}$ are $5.66 \times 10^{-13}, 16.12 \times 10^{-13}$, and $4.32 \times$ $10^{-14} \mathrm{~mL} \cdot \mathrm{m} \cdot \mathrm{m}^{-2} \cdot \mathrm{h}^{-1} \cdot \mathrm{atm}^{-1}$, respectively.

3.1.2. Testing System. As shown in Figure 1, the testing system consisted of four parts that were testing jar, intelligent measurement system of RH-temperature, adjustment system of RH-temperature, and gas concentration analysis system. In order to measure the temperature, $\mathrm{RH}$, and gas concentrations inside the metal jar, one RH-temperature sensor (RH: $10-100 \pm 2.0 \%$, temperature: $0-60 \pm 0.5^{\circ} \mathrm{C}$ ) and one gas pump were fixed on the upper portion of the jar and connected to intelligent measurement instrument of $\mathrm{RH}$-temperature and gas concentration analysis instrument (Illinois Ltd., USA, model $6600, \mathrm{O}_{2}$ range: $0.001-100 \pm 0.2 \%, \mathrm{CO}_{2}$ range: $0.1-100 \pm 2.0 \%)$, respectively.

The testing jar can be closed with metal cap or packaging film in order to conduct the airtight or permeability packaging testing. After packaging, the testing jars were placed in adjuster of relative humidity-temperature (Qingshen Ltd., Taiwan, model THS-D7C-100AS, temperature: $\left.0-100 \pm 0.5^{\circ} \mathrm{C}, \mathrm{RH}: 20-100 \pm 2.0 \%\right)$ to be stored in a testing condition.

3.1.3. Estimation of Respiration Model Parameter Values. The samples and the jars were pretreated at $8^{\circ} \mathrm{C}, 80 \% \mathrm{RH}$ for $4 \mathrm{~h}$. The normal air packages were applied to pack $570 \pm 10 \mathrm{~g}$ of samples using testing jars, which were closed with metal caps. The packages were stored at $8^{\circ} \mathrm{C}, 80 \% \mathrm{RH}$ for $48 \mathrm{~h}$. The concentrations of $\mathrm{O}_{2}$ and $\mathrm{CO}_{2}$ were measured every $2 \mathrm{~h}$. The parameter values of respiration rates were calculated according to closed system method. The experiment was simultaneously repeated three times.

Respiration rate data from above experiments were used for estimation of respiration model parameters values. Equations (3a) and (3b) were linearized as follows for the purpose of fitting the data:

$$
\begin{aligned}
& \frac{1}{R_{\mathrm{O}_{2}}}=\frac{1}{V_{m 1}}+\frac{K_{m 1}}{V_{m 1}} \frac{1}{\left[\mathrm{O}_{2}\right]}+\frac{1}{K_{u 1} V_{m 1}}\left[\mathrm{CO}_{2}\right], \\
& \frac{1}{R_{\mathrm{CO}_{2}}}=\frac{1}{V_{m 2}}+\frac{K_{m 2}}{V_{m 2}} \frac{1}{\left[\mathrm{O}_{2}\right]}+\frac{1}{K_{u 2} V_{m 2}}\left[\mathrm{CO}_{2}\right] .
\end{aligned}
$$

The multiple linear regression analysis for estimating the parameter values of respiration model was performed using the statistical software SAS.

3.1.4. Packaging and Storage of the Samples. First, normal air packages were applied to pack $480 \pm 10,700 \pm 10 \mathrm{~g}$ of samples using test jars, which were closed with LDPE films of constant area $0.177 \mathrm{~m}^{2}$.

In the second test, modified initial gas composition (3.5\% $\mathrm{O}_{2} / 11.0 \% \mathrm{CO}_{2} / 85.5 \% \mathrm{~N}_{2}$ ) packages were applied to pack $700 \pm 10 \mathrm{~g}$ of samples using testing jars. Gas mixtures were conducted using a gas mix machine (Desen Packaging Machine Ltd., China, model MA-35, $\mathrm{CO}_{2}, \mathrm{O}_{2}$, and $\mathrm{N}_{2}$ range: 0-90 $\pm 1 \%)$. The machine used cylinders of compressed oxygen, carbon dioxide, and nitrogen to prepare the gas mixtures of any required proportions of oxygen, carbon dioxide, and nitrogen. Before packaging, the testing jars were flushed with the required gas composition (initial RH: $31 \%$, temperature: $8^{\circ} \mathrm{C}$ ) for five minutes through the lower valve of the jars, and then the samples were placed in jars. In the meantime, the flush was kept; finally the jars were closed with LDPE films.

The samples, testing jars were conditioned at $8^{\circ} \mathrm{C}, 80 \%$ $\mathrm{RH}$ for $4 \mathrm{~h}$ before packaging. The packaging operation was conducted in a cold room at $8^{\circ} \mathrm{C}$. All packages were stored at $8^{\circ} \mathrm{C}, 80 \% \mathrm{RH}$ for $40 \mathrm{~h}$, with periodic sampling to measure the $\mathrm{RH}$ and temperature. Three replicates were used for each condition.

\subsection{Model Simplification and Numerical Analysis}

3.2.1. Simplification of the Kinetic Model. In terms of the above experiment conditions, the kinetic model can be simplified as follows.

(1) Since the headspace of package is small, thermal equilibrium between the produce and the headspace is assumed to be reached within a short time. Consequently, the heat caused by gas convection inside the package could be neglected, and the heat absorbed by gas inside the package in unit time can be simplified as [18]

$$
Q_{g}=W_{a} C_{a} \frac{d T_{\mathrm{in}}}{d t},
$$


TABLE 1: Parameter estimates of respiration model for Lentinula edodes at $8^{\circ} \mathrm{C}$.

\begin{tabular}{lcccc}
\hline Gas & $V_{m}\left(\mathrm{~mL} \cdot \mathrm{kg}^{-1} \cdot \mathrm{h}^{-1}\right)$ & $K_{m}(\%)$ & $K_{u}(\%)$ & $R^{2}$ \\
\hline $\mathrm{O}_{2}$ & 122.52 & 26.73 & -88.30 & 0.9824 \\
$\mathrm{CO}_{2}$ & 110.81 & 30.11 & -83.23 & 0.9575 \\
\hline
\end{tabular}

where $C_{a}$ is the specific heat of dry air inside the package $\left(\mathrm{J} \cdot \mathrm{kg}^{-1} \cdot \mathrm{k}^{-1}\right), T_{\text {in }}$ is the temperature of gas inside the package (k).

(2) Usually the temperature change inside package of produce is not notable [9]; its effect on the permeability of packaging film and the respiration model parameters can be ignored.

3.2.2. Numerical Analysis. Based on the experimental conditions and corresponding parameters, the numerical analysis of the simplified kinetic model and corresponding equations was conducted using the Adams-Moulton method to obtain the change of RH inside package.

\section{Results and Discussion}

4.1. Respiration Model Parameter Values of Lentinula edodes. The respiration rate data obtained from the closed system experiments were applied to fit (26a) and (26b). The estimated parameter values were presented in Table 1 . The regression equation fitted the data well with the coefficient of determination $R^{2}>0.95$.

4.2. Verification of the Kinetic Model. The model predictions were compared to the results of three sets of experiments. The experiments varied in product weight and initial gas composition.

Figures 2 and 3 compared the model predictions and experiment data for 480,700 g, Lentinula edodes and normal air packages, respectively. The results showed that the $\mathrm{RH}$ inside packages rose rapidly. In the packages with the masses of $480,700 \mathrm{~g}$, the $\mathrm{RH}$ inside packages reached saturation $(100 \% \mathrm{RH}) 12 \mathrm{~h}, 10 \mathrm{~h}$ later, respectively. The main reason was that the gas exchange inside and outside the package was slow because of the initial gas of air and the respiration and transpiration rates were a bit higher. As the mass of produce increased, the quality of vaporized moisture was enhanced, the headspace decreased, and the rising rate of the RH quickened. Meanwhile, the results showed good agreement between theoretical prediction and experimental results with a little higher theoretical result at the beginning of package and the time for RH to reach saturated state shortened about $1 \mathrm{~h}$ mainly because of the simplification in theoretical analysis and neglects of influences of some factors on energy changes.

Figure 4 compared the model prediction and experiment data for $700 \mathrm{~g}$ Lentinula edodes and modified initial gas composition packages. Comparing with the package of same mass with initial gas of air, the increasing rate of the $\mathrm{RH}$ inside package was slowed down greatly. About $22 \mathrm{~h}$ later, the $\mathrm{RH}$ reached saturation. The main reason is that modified

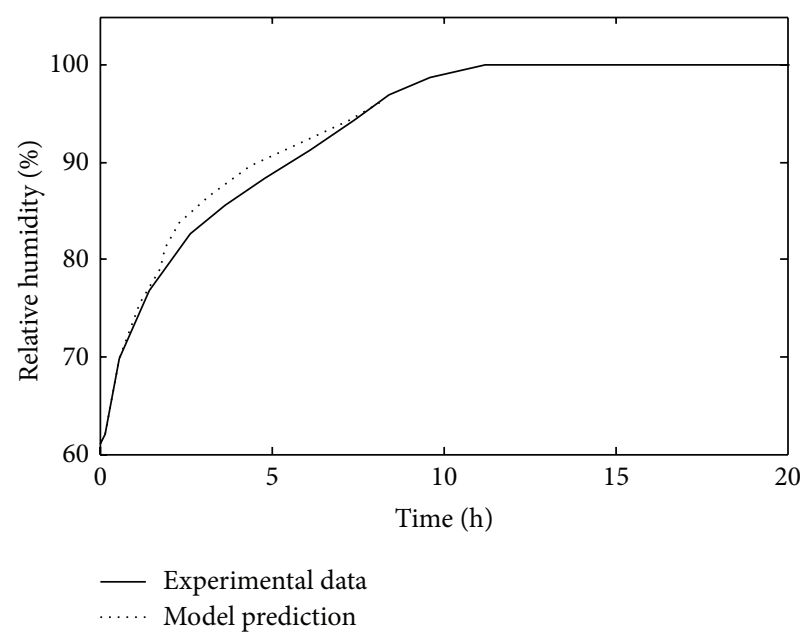

FIGURE 2: Relative humidity in packages of lentinula edodes during storage (mass: $480 \mathrm{~g}$; initial gas composition : normal air).

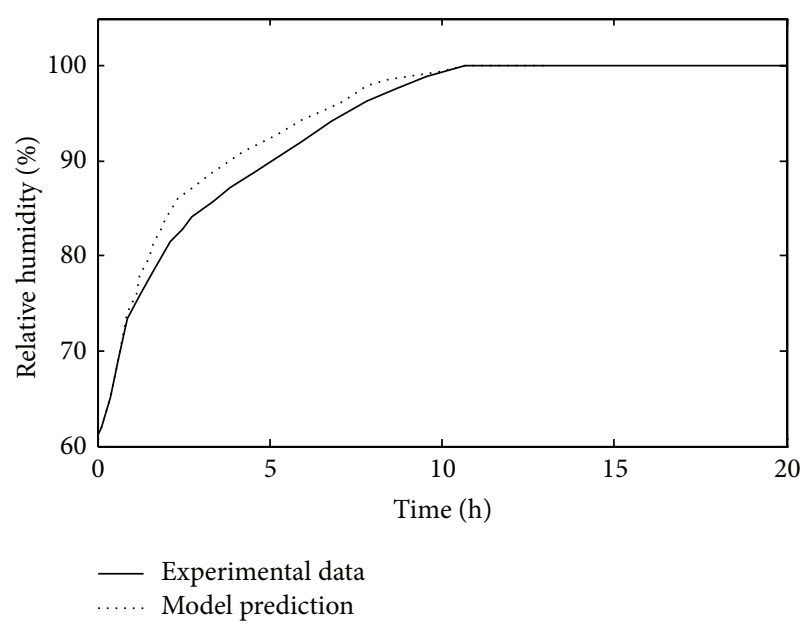

FIGURE 3: Relative humidity in packages of Lentinula edodes during storage (mass: $700 \mathrm{~g}$; initial gas composition: normal air).

atmosphere of low $\mathrm{CO}_{2}$ and high $\mathrm{O}_{2}$ decreased the respiration rates of produce and furthermore the transpiration rates were slowed down. This shows that initial gas composition could influence the RH inside package evidently. Similarly, the theoretical prediction agreed well with the experimental results.

The temperature change in three experimental conditions was shown in Figure 5. As a whole, the change of temperature inside packages was not much notable. During storage of $40 \mathrm{~h}$, corresponding to the experimental condition, the highest temperatures inside packages rose approximately $3.3^{\circ} \mathrm{C}, 4.3^{\circ} \mathrm{C}$, and $2.0^{\circ} \mathrm{C}$, respectively. Meanwhile, temperature inside packages decreased a little along with the prolonging of storage. This situation showed that the respiratory heat of sample was mainly absorbed to vaporize water vapor and result in the rapid rise of $\mathrm{RH}$ inside packages. The slightly increased temperatures justified our simplification of the kinetic model. 


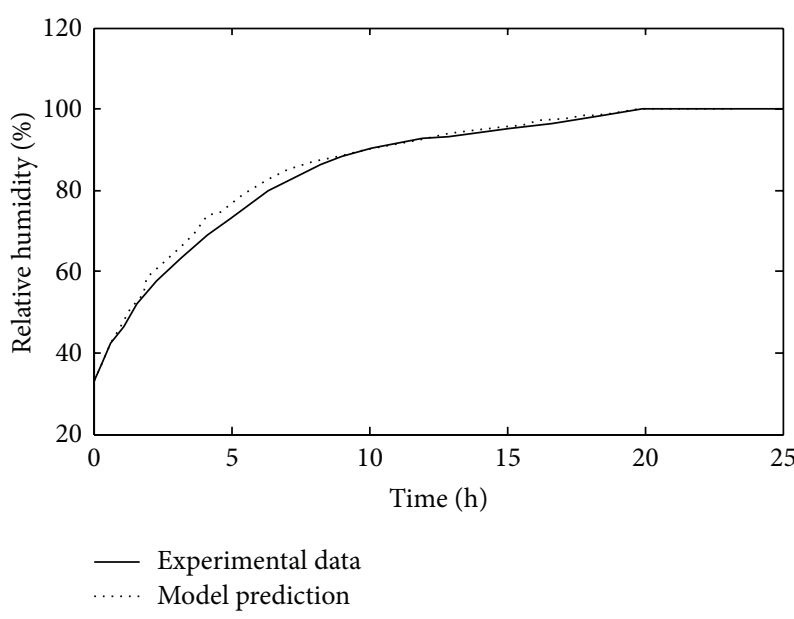

FIGURE 4: Relative humidity in packages of Lentinula edodes during storage (mass: $700 \mathrm{~g}$; initial gas composition: $3.5 \% \mathrm{O}_{2} / 11.0 \%$ $\mathrm{CO}_{2} / 85.5 \% \mathrm{~N}_{2}$ ).

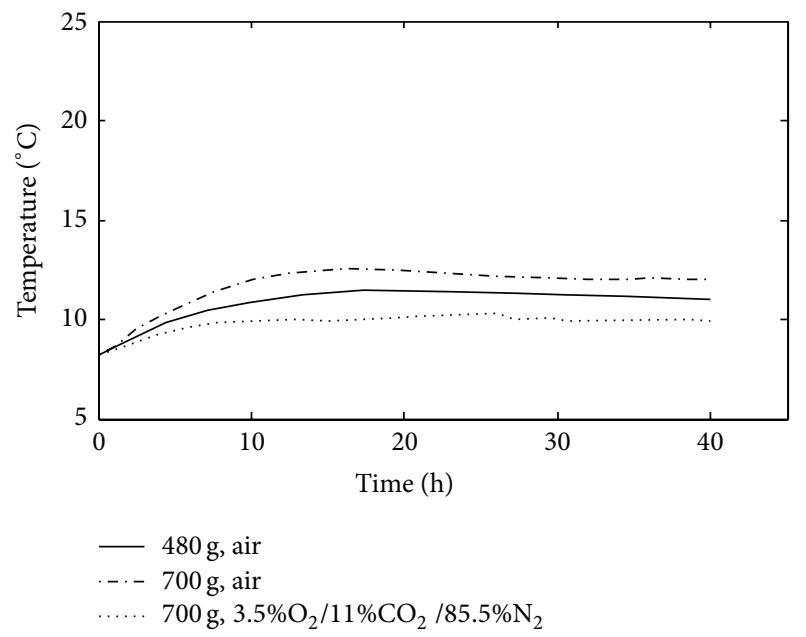

FIGURE 5: Temperature in packages of Lentinula edodes during storage.

\section{Conclusions}

An improved kinetic model was developed to predict the RH in MAP of produce based on heat exchange and gases mass transport phenomena across the package, gases heat convection inside the package, and mass and heat balances accounting for the respiration and transpiration behavior of fresh produce. The experiments of MAP containing fresh Lentinula edodes were conducted to obtain the $\mathrm{RH}$ and temperature inside packages. The results showed that

(1) as a whole, the model predictions agreed well with experimental results,

(2) initial gas composition had notable influence on the RH inside packages,

(3) the change of temperature inside package and effect of initial gas composition on temperature were not much notable.

\section{Conflict of Interests}

The author declares that there is no conflict of interests regarding the publication of this paper.

\section{Acknowledgment}

This work was supported by the Achievements Industrialization Project of Jiangsu province, Innovation and Technology Fund of Jiangnan University.

\section{References}

[1] L. Lu, "Theoretical research advances in theories for modified atmosphere packaging of fruits and vegetables," Transactions of the Chinese Society of Agricultural Engineering, vol. 21, no. 7, pp. 175-180, 2005.

[2] A. A. Kader, D. Zagory, and E. L. Kerbel, "Modified atmosphere packaging of fruits and vegetables," Critical Reviews in Food Science and Nutrition, vol. 28, no. 1, pp. 1-30, 1989.

[3] R. R. Deepak, S. O. Harinder, and B. Bangali, "Modified atmosphere packaging and its effect on quality and shelf life of fruits and vegetables-an overview," Journal of Food Science and Technology, vol. 39, no. 3, pp. 199-207, 2002.

[4] M. Cai and L. X. Lu, "Research on the variation of temperature and humidity in modified atmosphere packaging of strawberry," Packaging Engineering, vol. 26, no. 4, pp. 32-33, 2005.

[5] R. Villaescusa and M. I. Gil, "Quality improvement of Pleurotus mushrooms by modified atmosphere packaging and moisture absorbers," Postharvest Biology and Technology, vol. 28, no. 1, pp. 169-179, 2003.

[6] D. S. Lee, J. S. Kang, and P. Renault, "Dynamics of internal atmosphere and humidity in perforated packages of peeled garlic cloves," International Journal of Food Science and Technology, vol. 35, no. 5, pp. 455-464, 2000.

[7] P. Varoquaux and B. Gouble, "Films with adjustable permeability for preservation of fresh fruit and vegetable," Industries Alimentaires et Agricoles, vol. 114, no. 3, pp. 133-136, 1997.

[8] R. G. Evelo and J. Horst, "Modified atmosphere packaging of tomatoes; controlling gas and humidity," Packaging Technology and Science, vol. 9, no. 5, pp. 265-273, 1996.

[9] Y. Song, V. Nick, and K. L. Yam, "Modeling respirationtranspiration in a modified atmosphere packaging system containing blueberry," Journal of Food Engineering, vol. 53, no. 2, pp. 103-109, 2002.

[10] Y. Song, D. S. Lee, and K. L. Yam, "Predicting relative humidity in modified atmosphere packaging system containing blueberry and moisture absorbent," Journal of Food Processing and Preservation, vol. 25, no. 1, pp. 49-70, 2001.

[11] J. S. Kang and D. S. Lee, "A kinetic model for transpiration of fresh produce in a controlled atmosphere," Journal of Food Engineering, vol. 35, no. 1, pp. 65-73, 1998.

[12] R. Simpson, S. Almonacid, and C. Acevedo, "Development of a mathematical model for MAP systems applied to nonrespiring foods," Journal of Food Science, vol. 66, no. 4, pp. 561-567, 2001.

[13] R. Simpson, S. Almonacid, C. Acevedo, and C. Cortés, "Mathematical model to predict effect of temperature abuse in map systems applied to pacific hake (Merluccius australis)," Journal of Food Process Engineering, vol. 26, no. 5, pp. 413-434, 2003.

[14] R. Simpson, E. Corevic, and S. Rojas, "Modelling a modified atmosphere packaging system for fresh scallops (Argopecten 
purpuratus)," Packaging Technology and Science, vol. 20, no. 2, pp. 87-97, 2007.

[15] D. S. Lee, P. E. Haggar, J. Lee, and K. L. Yam, "Model for fresh produce respiration in modified atmospheres based on principles of enzyme kinetics," Journal of Food Science, vol. 56, pp. 1580-1585, 1991.

[16] K. Hayakwa, Y. S. Hening, and S. G. Gilbert, "Formulae for predicting gas exchange of fresh produce in polymeric film package," Journal of Food Science, vol. 40, pp. 186-191, 1975.

[17] D. D. Pitts and L. E. Sissom, Theory of Conduct Heat, Scientific Press, Beijing, China, 2002.

[18] W. W. Ma, Physics, Scientific Press, Beijing, China, 2002. 


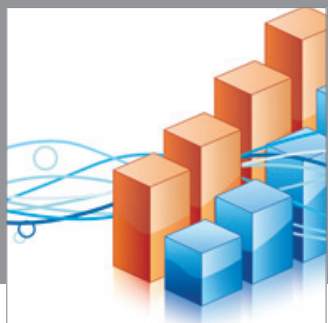

Advances in

Operations Research

mansans

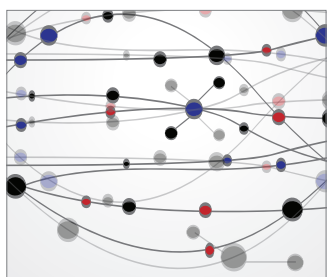

The Scientific World Journal
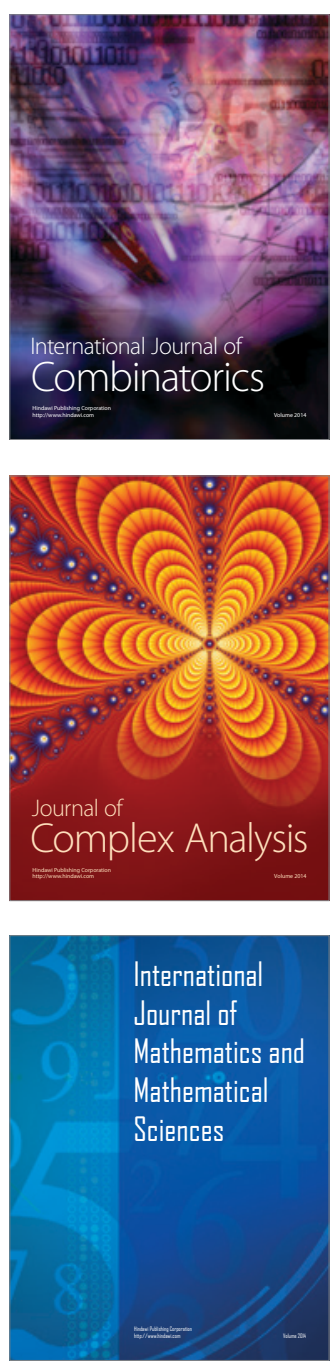
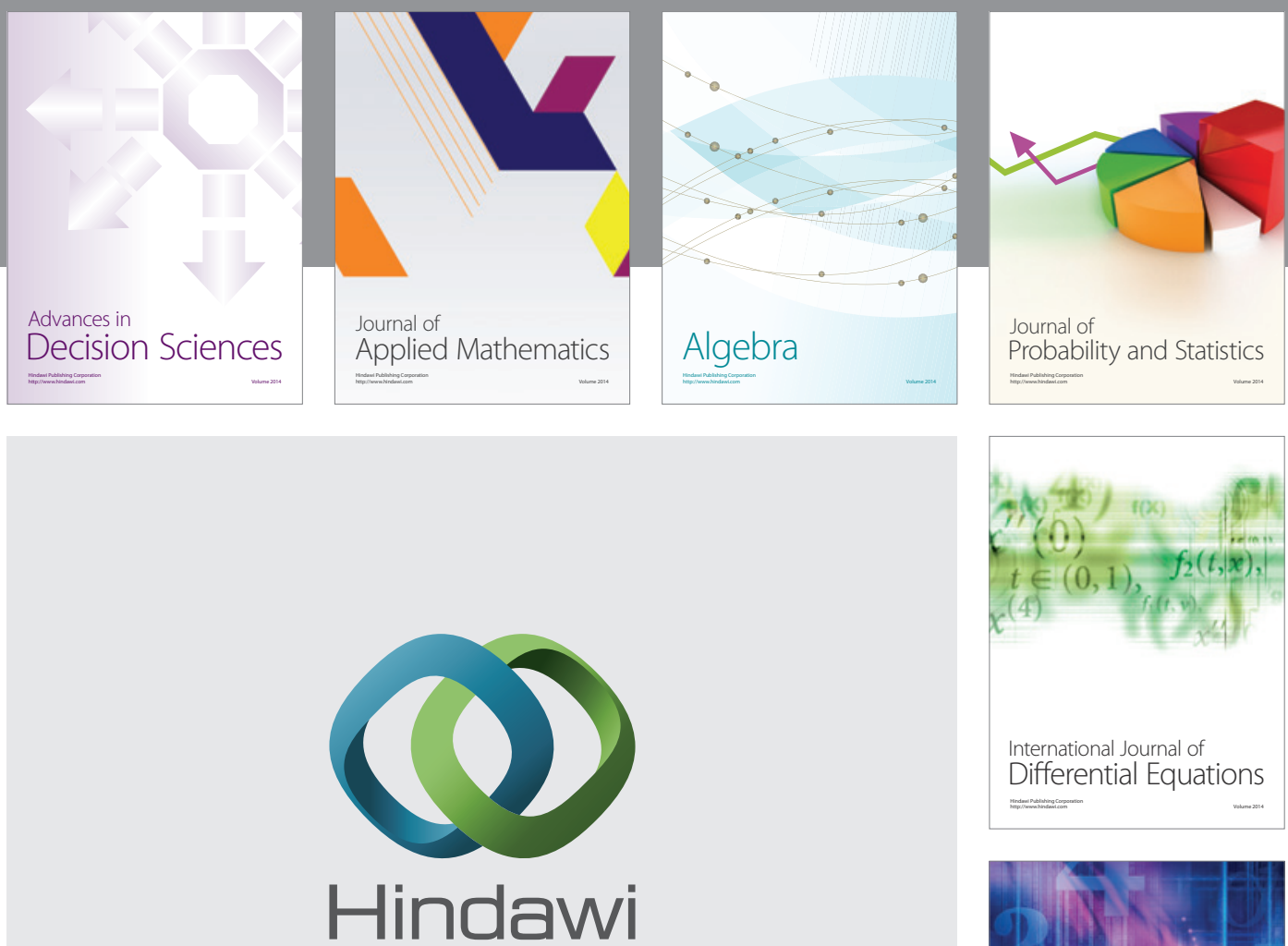

Submit your manuscripts at http://www.hindawi.com
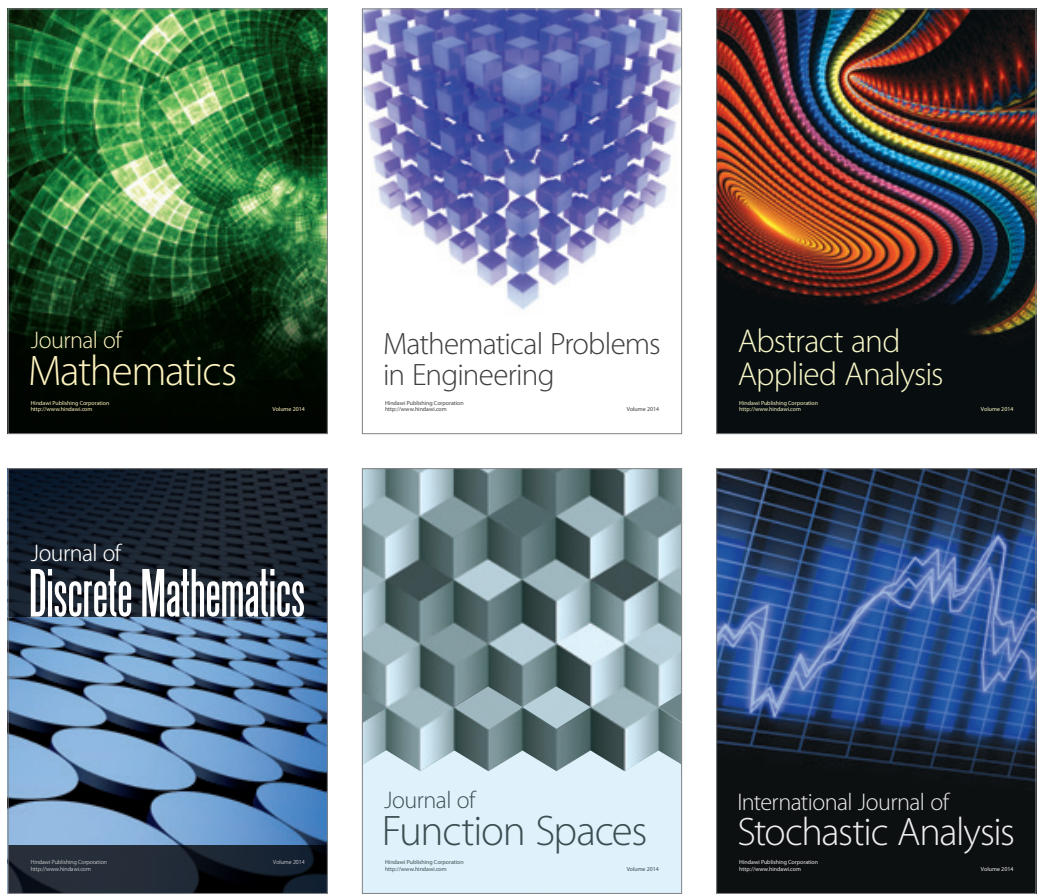

Journal of

Function Spaces

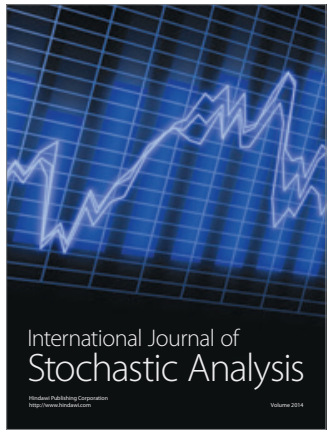

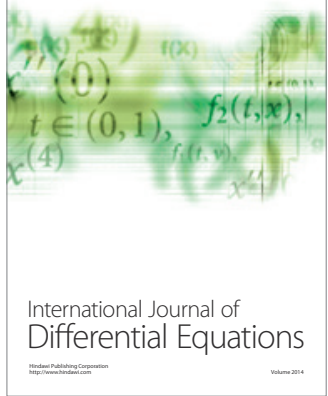
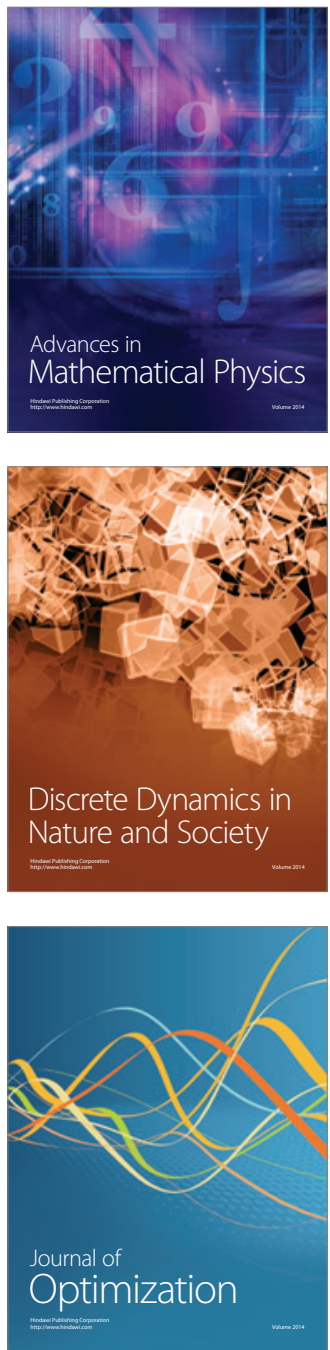